\title{
Naturally occurring radioactive materials in oil drilling wells in the Kurdistan region
}

\author{
A. H. Ahmed \\ Department of Physics, College of Science, \\ University of Salahaddin-Erbil, Kurdistan-Iraq, Erbil, Kurdistan-Iraq
}

\begin{abstract}
As the Kurdistan region starts a huge investment in the field of oil and gas, the assessment of radioactivity due to naturally occurring radioactive material becomes important. The dose rates and associated situational doses in the oil company and the radioisotope concentrations in the production mud and crude oil sample will be determined and then compared to the standard safe levels set internationally.

Keywords: norm, natural radioactivity, oil production, drilling wells.
\end{abstract}

\section{Scientific background}

Naturally occurring radioactive material (NORM) has been found in the Earth's crust and soil, the water we drink, the food we eat, the air we breathe, and the tissues of every living organism. The immense volume of (NORM) wastes produced annually by extracting industries throughout the world deserves to come to the attention of international and national environmental protection agencies and regulatory bodies. It is relatively easy to determine "concentrations", or specific activity levels, in the range of 1 part per trillion for radioactive materials. With radioactive elements so abundant and detection possible at such low levels, the presence of NORM in oil and gas operations shouldn't be surprising. In fact, this presence has been recognized since at least the 1930s.

The most significant aspects of NORM in oil production operations include original source, transport media, composition/radionuclides present, measurement methods, health/safety issues, waste classification, and waste disposal. 
The volumes of NORM wastes produced in oil and gas operations could reach levels so high that the existing low level radioactive waste facilities would be readily occupied by NORM if controlled disposal procedures were not adopted. On the other hand, NORM cannot just be ignored as being below radiological concern or lower than exempt concentration levels.

\section{Scientific scope of the project}

Recent concern has been devoted to the hazard arising from (NORM) in oil and gas facilities.

In several oil and gas producing states began to focus on NORM in the exploration and production segment of the industry, expressing concern over potential health and safety implications.

Unfortunately, thus far there is not enough information or assessments available concerning NORM wastes in oil blocks and wells drilled by industrial companies working in Kurdistan.

The project is proposed with the intention of examining, to the extent possible, the potential environmental and regulatory implications of NORM wastes being produced in selected oil blocks.

NORM wastes associated with oil and gas operations from scale deposits, separated sludge and water at different oil wells in the Kurdistan Region will be investigated. Concentrations of the uranium, thorium, and potassium $\left({ }^{40} \mathrm{~K}\right)$ series can be determined from high-resolution gamma-ray spectrometry

\section{Work plan}

1. Reviewing the original Kurdistan local map in which the exploring blocks indicated.

2. Preparing a site surveying plan to visit the wells.

3. Using the dose rate meters to determine the dose rates and occupational doses in the company, and mud samples will be collected according to standard sampling methods.

4. Starting the analysis within the available instrumentation and certifying the results by repeating the experiment with different methods regarding the accuracy and precision.

The solid state nuclear track detector technique will be used for activity and concentration measurements of the mud samples. Before any measurement the track detector should be calibrated for efficiency using the ${ }^{226} \mathrm{Ra}$ radioactive source. As well as the detector in its own determines the calibration factors for a wide range of radioisotopes which are included in its library. For each sample measurement the background will taken into account and subtracts from the water sample activities.

The method which is used in this work regards as a reliable method, and helps in understanding and determining a quantitative detection of the radioactivity due 
to ${ }^{238} \mathrm{U}$, and ${ }^{226} \mathrm{Ra}$ which are important for surveying and assessing the level of radioactivity in the well region.

Other methods of the gamma-ray spectroscopy using scintillation and High Pure Germanium detectors can be used as a more precise method to certify analyses with the aid of the Uranium and Thorium standard sources which are not available in our laboratory till now.

\section{Timetable}

Table 1: $\quad$ Timetable of work performance.

\begin{tabular}{|l|l|c|}
\hline No. & \multicolumn{1}{|c|}{ Activity } & Time period \\
\hline 1. & Plan design & 1 month \\
\hline 2. & Sampling and tests & 6 months \\
\hline 3. & Data analysis & 3 months \\
\hline 4. & Reporting (Editing) & 2 months \\
\hline \multicolumn{2}{|c}{ Total time } & $\mathbf{1 2 ~ m o n t h s}$ \\
\hline
\end{tabular}

\section{Expected outputs}

1. Determination of the dose rate and concentration of radio-elements including in the NORM within the well sites.

2. The production of scientifically approved base line data and reports to serve in the current and future development programs for assessing the NORM levels within the well sites.

3. Identification of the pollutant sources and postulating measures of mitigation and rectification

4. Initiation of sufficient number of skilled personnel in this field.

\section{References}

[1] Naturally Occurring Radioactive Material (NORM VI), Proceedings of an International Symposium, Marrakesh, Morocco, 22-26 March 2010.

[2] Guidelines for the Management of Naturally Occurring Radioactive Material (NORM) in the Oil \& Gas Industry, International Association of Oil \& Gas Producers, Report No. 412, September 2008.

[3] Azeri, Chirag \& Gunashli Full Field Development Phase 3, Environmental \& Socio-economic Impact Assessment, Final Report, October 2004. 